\title{
Analisis Potensi lahan Pertanian Pangan untuk Mendukung Ketahanan Pangan Kota BANDUNG
}

\author{
Potential Analysis of Agricultural Land to Support Food Security in Bandung City \\ Fahmi Rizal' ${ }^{1}$ dan Ganjar Herdiansyah ${ }^{2)}$ \\ ${ }^{1}$ Dosen Fakultas Teknologi Industri Pertanian, Universitas Pdjadjaran \\ ${ }^{2}$ Dosen Luar Biasa Fakultas Pertanian Universitas Padjadjaran \\ Jalan Raya Bandung-Sumedang Km 21, Jatinangor 40600 \\ E-mail :fahmi.rizal@unpad.ac.id
}

\begin{abstract}
ABSTRAK
Program ketahanan pangan di Kota Bandung saat ini dihadapkan pada semakin berkurangnya ketersediaan lahan petanian akibat tingginya laju konversi lahan ke non pertanian akibat pembangunan permukiman dan industri.Walaupun konsep pertanian kota mensyaratkan praktek berbasis teknologi, namun ketersediaan lahan juga tetap tidak bisa diabaikan keberadaannya.Tulisan ini mencoba untuk mengkaji potensi lahan pertanian, yaitu lahan yang sesuai peruntukannya bagi komoditas tanaman pangan di Kota Bandung.Metode penelitian menggunakan teknik analisis deskiptif melalui prosedur penilaian evaluasi kesesuaian lahan dengan aplikasi pemetaan yaitu Sistem Informasi Geografis (SIG).Hasil penelitian menemukan bahwa dibandingkan dengan kota-kota di Jawa Barat, luas lahan pertanian Kota Bandung masih cukup luas, namun laju konversi cukup tinggi mencapai 577.2 Ha per tahun selama periode Tahun 2010-2015.Potensi lahan yang sesuai peruntukannya untuk sawah dengan kategori S1 (sangat sesuai) mencapai $804.18 \mathrm{Ha}$, sedangkan untuk tanaman pangan (ubi jalar, ubi kayu, jagung, kacang tanah) termasuk kelas kesesuaian lahan S2 (sesuai) dan S3 (sesuai maginal) masing-masing seluas $37 \mathrm{Ha}$ dan $3.95 \mathrm{Ha}$.Dengan demikian, ketersediaan lahan potensial untuk pertanian di Kota Bandung tidak mencukupi untuk menyokong ketahanan pangan.Hal ini terbukti hingga saat ini kebutuhan pangan masyarakat Kota Bandung $80 \%$ tergantung pasokan dari luar Kota Bandung.
\end{abstract}

Kata Kunci: Ketahanan Pangan, Pertanian Kota, Kesesuaian Lahan, Ketersediaan Lahan

\begin{abstract}
Food security policy in Bandung city faced with the decreasing availability of land due to the high rate of conversion of agricultural land to non-agricultural for settlement, construction and industry. Although the concept of urban agriculture requires practice based technology, but also the availability of land still can not be ignored its existence. This paper endeavour to assess the potential of agricultural land, in term of land suitable for food crops. The research method used the descriptive techniques through land suitability evaluation assessment procedures with using Geographic Information System (GIS). The study found that compared with other cities in West Java, Bandung City area of agricultural land is still quite large, but the conversion rate is quite high at 577.2 Ha per year during the period 2010-2015. Potential suitable land for paddy with the category S1 (Highly suitable) reached 804.18 hectares, while for crops (yams, cassava, maize, groundnuts) including land suitability classes S2 (moderately suitable) and S3 (marginally suitable) respectively covering 37 ha and $3.95 \mathrm{Ha}$. Thus, the potential availability of land for agriculture in Bandung insufficient to support food security. It is evident to this day the food needs of people in Bandung $80 \%$ depending on supplies from outside the city of Bandung.
\end{abstract}

Keyword: food security, urban agriculture, land evaluation, land availability

Diterima : 5 Juli 2016; Disetujui : 26 Agustus 2016 ; Online Published : 31 Oktober 2016 


\section{PENDAHULUAN}

Mengacu pada laporan dari UNDP (2004), luas lahan pertanian pangan per kapita(luas lahan sawah ditambah lahan tadah hujan) Indonesia sangat minimal di banding negara lain yaitu sebesar $360 \mathrm{~m}^{2}$, masih kalah dari Vietnam, India, Bangladesh, China yang memiliki luas lahan perkapitanya berturutturut960 $\mathrm{m}^{2}, 52 \mathrm{~m}^{2}, 655 \mathrm{~m}^{2}, 1120 \mathrm{~m}^{2}$. Bahkan sangat jauh dibanding dengan Negara di Eropa dan Amerika yang luas lahan pertanian perkapita nya diatas $6000 \mathrm{~m}^{2}$.Padahal, ketersediaan lahan dalam usaha pertanian merupakan conditio sine-quanon (syarat mutlak) untuk mewujudkan ketahanan dan kemandirian pangan secara nasional.

Meningkatnya pertambahan jumlah penduduk dan dinamika kebutuhan pembangunan di setiap daerah secara langsung atau tidak langsung 'memaksa' terjadinya perubahan penggunaan lahan-lahan pertanian pangan yang cukup tinggi, khususnya sawah. Laju rata-rata konversi lahan sawah di Kota Bandung dibandingkan dengan delapan kota lain di Jawa Barat dari Tahun 2009-2014 merupakan yang tertinggi mencapai 137 hektar,diikuti oleh Kota Depok dan Kota Sukabumi yaitu $75 \mathrm{Ha}$ dan $71 \mathrm{Ha}$ (Pusat Data dan Informasi Kementerian Pertanian, 2015). Luas lahan sawah Kota Bandung pada Tahun 2009 mencapai 1990 $\mathrm{Ha}$, menyusut signifikan menjadi $988 \mathrm{Ha}$ di Tahun 2014 disebabkan oleh peningkatan laju konversi ke non pertanian (Pusat Data dan Informasi Kementerian Pertanian, 2015).

Penurunan luas lahan sawah Kota Bandung berdampak terhadap penurunan produksi padi sebagai bahan makanan utama masyarakat kota Bandung yang berjumlah 2.4 juta orang (BPS Jawa Barat Dalam Angka, 2015). Tren pertambahan penduduk dan kebutuhan pembangunan yang terus meningkat, sementara luasan lahan pertanian terus menurun merupakan masalah serius bagi pasokan pangandi Kota Bandung.Kebutuhan pangan masyarakat Kota Bandung, $80 \%$ mengandalkan pasokan dari dari luar wilayah Kota Bandung (Renstra Dinas Pertanian dan Ketahanan Pangan Kota Bandung 2013-2018). Kondisi seperti ini menunjukkan dependensi sektor pangan Kota
Bandung terhadap wilayah lain cukup tinggi sehingga sulit untuk mencapai kondisi terpenuhinya pangan rumah tangga yang tercermin dari tersedianya pangan yang cukup, baik jumlah maupun mutunya, aman, merata, dan terjangkau

Penilaian terhadap potensi lahan pertanian pangan menjadi penting sebagai basis data untuk mengetahui berapa luas ketersediaan lahan yang cocok untuk budidaya tanaman pangan.Penilaian lahan pertanian yang potensial dapat diketahui melalui evaluasi kesesuaian lahan yaitu dengan caramengklasifikasikan lahan potensial kedalamkelas S1 (sangat sesuai), S2 (sesuai) dan S3 (sesuai marginal).

\section{METODOLOGI PENELITIAN}

\section{Bahan Penelitian}

Bahan yang digunakan dalam kajian ini diantaranya Peta Topografi Kota Bandung Skala 1: 50.000 Peta PenggunaanLahanSkala 1: 50.000 Peta Jenis Tanah skala 1: 50.000 Peta RBI Skala 1:50.000. Peralatan yang digunakan Laptop, Software Arc GIS Versi 10.1, Blanko isian untuk mencatat pengamatan lapangan Soil Munsell Color Chart untuk melihat warna tanah Bor tanah (auger/core) tipe belgi untuk mengambil contoh tanah pada tiap SPL, pH meter.

\section{Metode Penelitian}

Metode penelitian menggunakan pendekatan deskriptif melalui teknik analisis evaluasi kesesuian lahan untuk menilai potensi lahan petanian pangan Kota Bandung.Penentuan kelas kesesuaian lahan dilakukan dengan menyepadankan (matching) antara kualitas dan karakteristik lahan sebagai parameter dengan kriteria kelas kesesuaian lahan yang telah disusun berdasarkan persyaratan tumbuh tanaman.Penentuan kelas kesesuaian lahan ini mengacupada sistem kesesuaian lahan yang disusun oleh Pusat Penelitian Tanah dan Agroklimat (Puslittanak) Tahun 1994.

\section{Posedur dan Tahapan Penelitian}

1. Penyusunan karakteristik lahan 
Karakteristik lahan yang merupakan gabungan dari sifat-sifat lahan dan lingkungannyaKarakteristik lahandiuraikan pada setiap satuan peta lahan (SPL)dari peta tanah, yang meliputi:bentuk wilayah/lereng, drainase tanah, kedalaman tanah, tekstur tanah (lapisanatas 0-30 cm, dan lapisan bawah 30-50 cm), pH tanah, Data iklim terdiri dari curah hujan rata-rata tahunan dan jumlah bulan kering, serta suhu udara diperoleh dari stasiun pengamat iklim.

2. Penyusunan persyaratan tumbuh tanaman/penggunaan lahan

Persyaratan tumbuh dapat diperoleh dari berbagai referensi, seperti pada Djaenudin et al. (2003) dan berdasarkan Peraturan Menteri Pertanian Nomor 79 Tahun 2013 Tentang Pedoman Kesesuaian Lahan Pada Komoditas Tanaman Pangan.

2. Proses pencocokan (matching)

Setelah data karakteristik lahan tersedia, maka proses selanjutnya adalah evaluasi lahan yang dilakukan dengan cara matching (mencocokan) antara karakteristik lahan pada setiap satuan peta tanah (SPT) dengan persyaratan tumbuh/penggunaan lahan. Hasil penilaian berupa kelas dan subkelas kesesuaian lahan dari tanaman yangdinilai ditentukan oleh faktor pembatas terberat. Faktor pembatas tersebut dapatterdiri dari satu atau lebih tergantung dari karakteristik lahannya.

3. Kesesuaian lahan terpilih/penentuan arahan penggunaan lahan untuk tanaman Untuk menyusun arahan penggunaan lahan pertanian yang berkelanjutan perlu dipertimbangkan prioritas daerah dan penggunaan lahanaktual. Dalam penyusunan kesesuaian lahan pertanian berkelanjutan terpilih ini, digunakan struktur klassifikasi menurut kerangka FAO (1976) sebagai berikut:

Kelas Sangat sesuai: Lahan tidak S1 mempunyai faktor pembatas yang berarti atau nyata terhadap penggunaan secara berkelanjutan, ataufaktor pembatas bersifat minor dan tidak akan berpengaruhterhadap produktivitas lahan secara nyata.

Kelas Cukup sesuai:Lahan mempunyai S2 faktor pembatas, dan faktor pembatas ini akan berpengaruh terhadap produktivitasnya, memerlukan tambahan masukan (input). Pembatas tersebut biasanyadapat diatasi oleh petani sendiri

Kelas Sesuai marginal:Lahan S3 mempunyai faktor pembatas yang berat,dan faktor pembatas ini akan sangat berpengaruh terhadapproduktivitasnya, memerlukan tambahan masukan yang lebihbanyak daripada lahan yang tergolong S2. Untukmengatasi faktorpembatas pada S3 memerlukan modal tinggi,sehingga perlu adanyabantuan atau campur tangan (intervensi) pemerintah atau pihakswasta.

Kelas Tidak sesuai: Lahan mempunyai $\mathrm{N}$ faktor pembatas yang sangat berat dan/atau sulit diatasi.

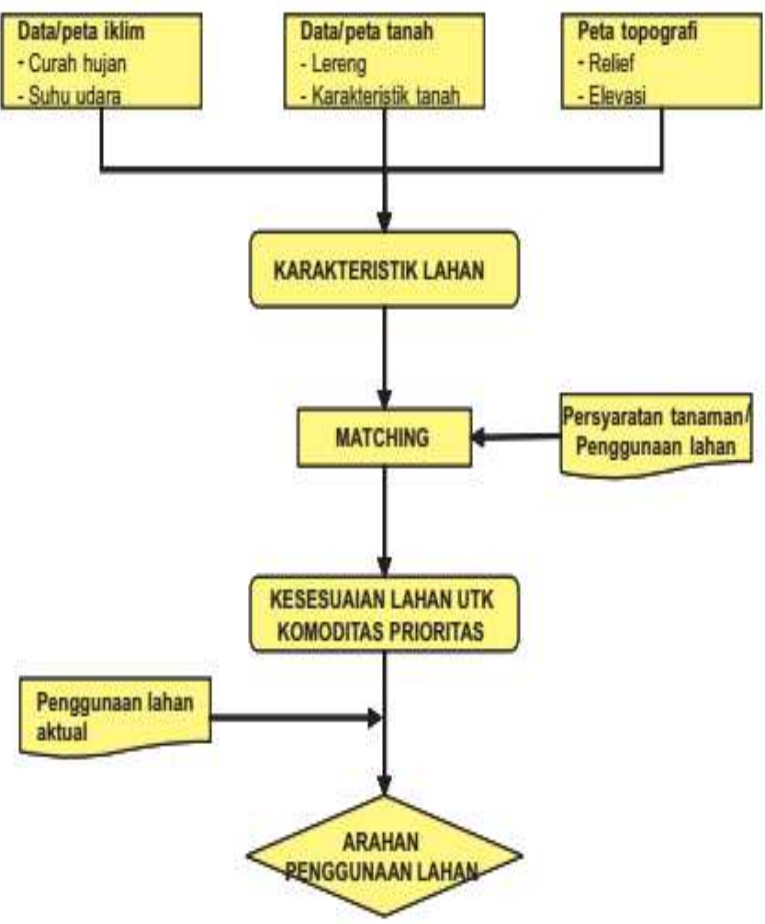

Gambar 1. Bagan Alir Penelitian 


\section{HASIL DAN PEMBAHASAN}

\section{Gambaran Umum Lahan Pertanian Kota Bandung}

Jenis Tanah. Berdasarkan pengamatan di daerah penelitian Ordo tanah termasuk ke dalam alluvial dan latosol. Penyebaran tanah alluvial berada pada wilayah selatan dan tengah dari Kota Bandung, sedangkan tanah latosol berada di bagian utara kota Bandung. Tanah aluvial adalah tanah yang dibentuk dari lumpur sungai yang mengendap di dataran rendah yang memiliki sifat tanah yang subur dan cocok untuk lahan pertanian.Sifatnya tergantung dari asalnya yang dibawa oleh sungai. Tanah aluvial yang berasal dari gunung api umumnya subur karena banyak mengandung mineral.

Pada umumnya tanah Latosol ini kadar unsur hara dan organiknya cukup rendah, sedangkan produktivitas tanahnya dari sedang sampai tinggi. Tanah ini memerlukan input yang memadai. Tanaman yang bisa ditanam didaerah ini adalah padi (persawahan), sayur-sayuran dan buah-buahan, palawija, kemudian kelapa sawit, karet, cengkeh, kopi dan lada.

Penggunaan Lahan. Hasil interpretasi citra tahun 2010 untuk daerah penelitian menunjukkan sebaran penggunaan lahan adalah hutan primer seluas 0,56 $\mathrm{Ha}$, hutan sekunder $0,67 \mathrm{Ha}$, kebun/perkebunan 319,05 Ha $(1,81 \%)$, ladang/tegalan $453,22 \mathrm{Ha} \quad(2,57 \%)$, sawah $3.269,45 \mathrm{Ha}(18,57 \%)$, semak/belukar $328,10 \mathrm{Ha}$ $(1,86 \%)$, perairan $8,60 \mathrm{Ha}(0,05 \%)$ dan lahan terbangun seluas $13.229,46 \mathrm{Ha}(75,13 \%)$ dari total luas daerah penelitian.

Hasil analisis peta penggunaan lahan tahun 2010 di lokasi penelitian menunjukkan bahwa penggunaan lahan terbangun relatif menyebar mulai dari bagian utara sampai ke selatan dan bagian barat ke timur, sedangkan penggunaan lahan hutan primer dan hutan sekunder berada pada bagian utara kota bandung. Penggunaan lahan sawah berada di timur lokasi penelitian penggunaan lahan ladang berada secara menyebar pada semua bagian kota bandung.

Hasil analisis peta citra pada penggunaan lahan pertanian tahun 2015 di kota bandung mengalami penurunan menjadi 856,32 $\mathrm{Ha}$. Hal ini karena adanya konversi lahan pertanian menjadi lahan terbangun, seiring dengan semakin bertambahnya penduduk Hasil interpretasi citra satelit tahun 2015 menunjukkan adanya penurunan luasan penggunaan lahan hutan primer dan sekunder, ladang/tegalan, semak belukar dan sawah.

Tabel 1. Penggunaan Lahan Kota Bandung

\begin{tabular}{|c|c|c|c|c|}
\hline \multirow[t]{2}{*}{ No. } & \multirow{2}{*}{$\begin{array}{c}\text { Penggunaan } \\
\text { Lahan }\end{array}$} & \multicolumn{2}{|c|}{ Luas } & \multirow{2}{*}{$\begin{array}{c}\text { Perubahan } \\
\mathrm{Ha}\end{array}$} \\
\hline & & Tahun 2010 & Tahun 2015 & \\
\hline 1 & Hutan Primer & 0.56 & 0.16 & -0.4 \\
\hline 2 & Hutan Sekunder & 0.67 & 0.37 & -0.3 \\
\hline 3 & $\begin{array}{l}\text { Kebun/Perkebun } \\
\text { an }\end{array}$ & 319.05 & 369.75 & 50.7 \\
\hline 4 & Ladang/Tegalan & 453.22 & 52.14 & -401.08 \\
\hline 5 & Sawah & $3,269.45$ & 804.18 & $-2,465.27$ \\
\hline 6 & Semak/Belukar & 328.1 & 28.1 & -300 \\
\hline 7 & $\begin{array}{l}\text { Sungai/Danau/ } \\
\text { Waduk/Situ }\end{array}$ & 8.6 & 8.6 & - \\
\hline 8 & Terbangun & $13,229.46$ & $16,345.81$ & $3,116.35$ \\
\hline & Total & $17,609.11$ & $17,609.11$ & \\
\hline
\end{tabular}

Sumber: Peta Rupa Bumi Indonesia,2014 (Data Diolah)

Terjadi peningkatan luasan lahan terbangun dari $13.229,46$ ha menjadi 16.345 , $81 \mathrm{Ha}$ dan lahan kebun/perkebunan dari 319,05 Ha menjadi 369,75 Ha. Penurunan penggunaan lahan pertanian di Kota Bandung akibat dari adanya alih fungsi lahan menjadi lahan terbangun atau pemukiman dan industri.

\section{Analisis Potensi Lahan Pertanian Pangan Kota Bandung}

Satuan Peta Lahan. Satuan Peta Lahan (SPL) merupakan pengelompokan lahan kedalam satuan-satuan peta lahan yang masingmasing mempunyai sifat-sifat yang sama. Dalam pembuatan SPL kota Bandung sifat-sifat lahan yang diamati meliputi iklim (curah hujan), penggunaan lahan (sawah dan ladang/tegalan), kemiringan lereng $(0-3 \%, 3-8 \%, 8-15 \%, 15-25 \%$, $25-40 \%, 40-60 \%$ dan $>60 \%$ ), dan jenis tanah (aluvial dan latosol). Sifat-sifat lahan ini di tumpangsusun-kan (overlay) menjadi Satuan Peta Lahan yang dijadikan acuan dalam survey lapangan dengan pengamatannya. Hasil tumpang susun (overlay) peta tematik di atas menghasilkan 7 SPL untuk kota Bandung dengan sifat pembeda dominan adalah kemiringan lereng. Lokasi SPL dan luasan masing-masing per Kelurahan dapat dilihat pada Tabel 2.

Faktor Pembatas. Evaluasi lahan merupakan suatu penilaian yang memperhatikan sifat-sifat lingkungan suatu wilayah yang 
mempengaruhi pertumbuhan tanaman dirinci ke dalam kualitas lahan (land qualities) dan setiap kualitas lahan dapat terdiri lebih dari satu karakteristik lahan (land characteristics). Beberapa karakteristik lahan di Kota Bandung umumnya mempunyai hubungan satu sama lainnya. Kualitas dan karakteristik lahan tersebut dalam evaluasi lahan disebut sebagai faktor pembatas karena keberadaan dapat menghambat dalam penggunaan tertentu (tanaman pertanian).

Jumlah faktor pembatas SPL di Kota Bandung cukup banyak, tetapi untuk kepentingan evaluasi lahan pertanian berkelanjutan, bisa dipilih dan disesuaikan dengan keperluan.Dalam kajian ini, faktor pembatas yang dinilai terdiri dari 6 kualitas lahan yang diuraikan menjadi 11 karakteristik lahan.

Tabel 2. Penilaian Karakteristik Lahan pada masing-masing SPL

\begin{tabular}{|c|c|c|c|c|c|c|c|}
\hline Karakteristik Lahan & SPL 1 & SPL 2 & SPL 3 & SPL 4 & SPL 5 & SPL 6 & SPL 7 \\
\hline Lereng (\%) & $0-3 \%$ & $3-8 \%$ & $8-15 \%$ & $15-25 \%$ & $25-40 \%$ & $40-60 \%$ & $>60 \%$ \\
\hline $\begin{array}{l}\text { Batuan dipermukaan } \\
(\%)\end{array}$ & - & - & - & - & - & - & - \\
\hline $\begin{array}{l}\text { Singkapan batuan } \\
(\%)\end{array}$ & - & - & - & - & - & - & - \\
\hline $\begin{array}{l}\text { Jumlah curah hujan } \\
\text { tahunan }\end{array}$ & $\begin{array}{l}1500- \\
2000\end{array}$ & $\begin{array}{l}1500- \\
2000\end{array}$ & $\begin{array}{l}1500- \\
2000\end{array}$ & $\begin{array}{l}1500- \\
2000\end{array}$ & $\begin{array}{l}1500- \\
2000\end{array}$ & $\begin{array}{l}1500- \\
2000\end{array}$ & $\begin{array}{l}1500- \\
2000\end{array}$ \\
\hline Jumlah bulan kering & - & - & - & - & - & - & - \\
\hline $\begin{array}{l}\text { Temperatur rata-rata } \\
\text { tahunan }\left({ }^{\circ} \mathrm{C}\right)\end{array}$ & 23.5 & 23.5 & 23.5 & 23.5 & 23.5 & 23.5 & 23.5 \\
\hline Kelas drainase & buruk & Buruk & sedang & baik & baik & baik & baik \\
\hline Tekstur tanah & liat & liat & $\begin{array}{l}\text { Lempung } \\
\text { berliat }\end{array}$ & $\begin{array}{l}\text { Lempung } \\
\text { berliat }\end{array}$ & $\begin{array}{c}\text { liat } \\
\text { berdebu }\end{array}$ & $\begin{array}{l}\text { Liat } \\
\text { berdebu }\end{array}$ & $\begin{array}{c}\text { Liat } \\
\text { berdebu }\end{array}$ \\
\hline $\begin{array}{l}\text { Kedalaman efektif } \\
(\mathrm{cm})\end{array}$ & 100 & 100 & 100 & 150 & 155 & 200 & 200 \\
\hline $\begin{array}{l}\text { Tingkat Bahaya } \\
\text { Erosi (TBE) }\end{array}$ & $\begin{array}{l}\text { sangat } \\
\text { ringan }\end{array}$ & Ringan & sedang & berat & berat & $\begin{array}{c}\text { sangat } \\
\text { berat }\end{array}$ & $\begin{array}{c}\text { sangat } \\
\text { berat }\end{array}$ \\
\hline $\begin{array}{l}\text { Lamanya } \\
\text { banjir/genangan }\end{array}$ & tergenang & tergenang & - & - & - & - & - \\
\hline
\end{tabular}

\section{Potensi Lahan PotensialPertanian Pangan}

Hasil penilaian kesesuaian lahan aktual menunjukkan SPL 1 memiliki kriteria S1 (sesuai) dengan luas $752,85 \mathrm{Ha}$, penggunaan lahan eksisting adalah lahan sawah yang berada di bagian timur kota Bandung. SPL 2 memiliki kriteria S2 (cukup sesuai) dengan memiliki factor pembatas dominan adalah kemiringan lereng yaitu 3-8\%.SPL 3 memiliki kriteria S3 (sesuai marginal) dengan faktor pembatas adalah kemiringan lereng yang berada pada kisaran 8$15 \%$. Pada SPL 4,5,6 dan SPL 7 memiliki kriteria $\mathrm{N}$ (tidak sesuai untuk saat ini) dengan faktor pembatas kemiringan lereng lebih dari $15 \%$. Kemiringan seperti ini tidak sesuai dengan ditanami tanaman pangan, sehingga kejadian erosi akan semakin besar.
Tabel 4. Ketersediaan Lahan Pertanian Potensial Kota Bandung

\begin{tabular}{|c|c|c|c|c|c|c|}
\hline \multirow{2}{*}{ SPL } & \multicolumn{2}{|c|}{ Koordinat } & \multirow{2}{*}{$\begin{array}{c}\text { Kesesu } \\
\text { aian } \\
\text { Lahan }\end{array}$} & \multirow{2}{*}{$\begin{array}{l}\text { Faktor } \\
\text { Pembatas }\end{array}$} & \multicolumn{2}{|c|}{ Luas } \\
\hline & Lintang & Bujur & & & $\mathrm{Ha}$ & $\%$ \\
\hline 1 & 656 '30.753"S & $10741 ' 59.681 " \mathrm{E}$ & S1 & - & 752.85 & 87.92 \\
\hline 2 & 654'40.735"S & 107\%3'7.633"E & S2 & $\begin{array}{c}\text { Kemiringan } \\
\text { lereng }\end{array}$ & 51.33 & 5.99 \\
\hline 3 & 654'20.705"S & 107'43'48.536"E & S3 & $\begin{array}{c}\text { Kemiringan } \\
\text { lereng }\end{array}$ & 37.84 & 4.42 \\
\hline 4 & $653^{\prime} 41.24 " \mathrm{~S}$ & 10742'41.198"E & $N$ & $\begin{array}{c}\text { Kemiringan } \\
\text { lereng }\end{array}$ & 3.95 & 0.46 \\
\hline 5 & 653'32.418"S & 10742'38.257"E & $\mathrm{N}$ & $\begin{array}{c}\text { Kemiringan } \\
\text { lereng }\end{array}$ & 1.68 & 0.2 \\
\hline 6 & 651'31.89"S & 10736 '48.853"E & $\mathrm{N}$ & $\begin{array}{c}\text { Kemiringan } \\
\text { lereng }\end{array}$ & 5.15 & 0.6 \\
\hline 7 & $650 ' 57.381 " \mathrm{~S}$ & $107^{\circ} 36^{\prime} 6.232^{\prime \prime E}$ & $\mathrm{~N}$ & $\begin{array}{c}\text { Kemiringan } \\
\text { lereng }\end{array}$ & 3.51 & 0.41 \\
\hline
\end{tabular}

Sumber : Data Primer, 2016 (diolah)

Usaha perbaikan perlu dilakukan untuk meningkatkan kesesuaian lahan aktual.Target pengelolaan dan usaha perbaikan lahan untuk pengembangan lahan pertanian berkelanjutan adalah disajikan pada Tabel 4 .

Tabel 4. Jenis Usaha Perbaikan Lahan Petanian Potensial

\begin{tabular}{|c|c|c|c|c|c|}
\hline \multirow{2}{*}{ SPL } & \multirow{2}{*}{$\begin{array}{c}\text { Potensi } \\
\text { Lahan } \\
\text { Aktual }\end{array}$} & \multirow{2}{*}{ Usaha Perbaikan } & \multirow{2}{*}{$\begin{array}{l}\text { Potensi } \\
\text { Lahan } \\
\text { setelah } \\
\text { Perbaikan }\end{array}$} & \multicolumn{2}{|c|}{ Luas } \\
\hline & & & & $\mathrm{Ha}$ & $\%$ \\
\hline 1 & S1 & - & S1 & 752.85 & 87.92 \\
\hline 2 & S2 & $\begin{array}{l}\text { Pembuatan dan } \\
\text { perbaikan teras }\end{array}$ & S1 & 51.33 & 5.99 \\
\hline 3 & S3 & $\begin{array}{l}\text { Pembuatan dan } \\
\text { perbaikan teras }\end{array}$ & S2 & 37.84 & 4.42 \\
\hline 4 & $\mathrm{~N}$ & $\begin{array}{l}\text { Pembuatan dan } \\
\text { perbaikan teras }\end{array}$ & S3 & 3.95 & 0.46 \\
\hline 5 & $\mathrm{~N}$ & $\begin{array}{l}\text { Pembuatan dan } \\
\text { perbaikan teras }\end{array}$ & S3 & 1.68 & 0.2 \\
\hline 6 & $\mathrm{~N}$ & Konservasi & $\mathrm{N}$ & 5.15 & 0.6 \\
\hline 7 & $\mathrm{~N}$ & Konservasi & $\mathrm{N}$ & 3.51 & 0.41 \\
\hline \multicolumn{4}{|c|}{ tal Lahan Pertanian } & 856.32 & 100 \\
\hline
\end{tabular}

Analisis terhadap potensi lahan pertanian dimaksudkan agar lahan yang akan dikembangkan layak usaha yaitu lahannya sesuai untuk pertanian dan terbebas dari kemungkinan klaim oleh penduduk setempat. Hasil penilaian kesesuaian lahan potensial mendapatkan lahan yang sesuai untuk lahan pertanian di Kota Bandung seluas 847,66 Ha. Dengan asumsi bahwa lahan-lahan yang sedang digunakan atau pernah digunakan untuk kegiatan pertaniannya dapat dibebaskan atau diserahkan kepada pemerintah daerah maka lahan tersebut dapat dikembangkan untuk lahan pertanian berkelanjutan. 


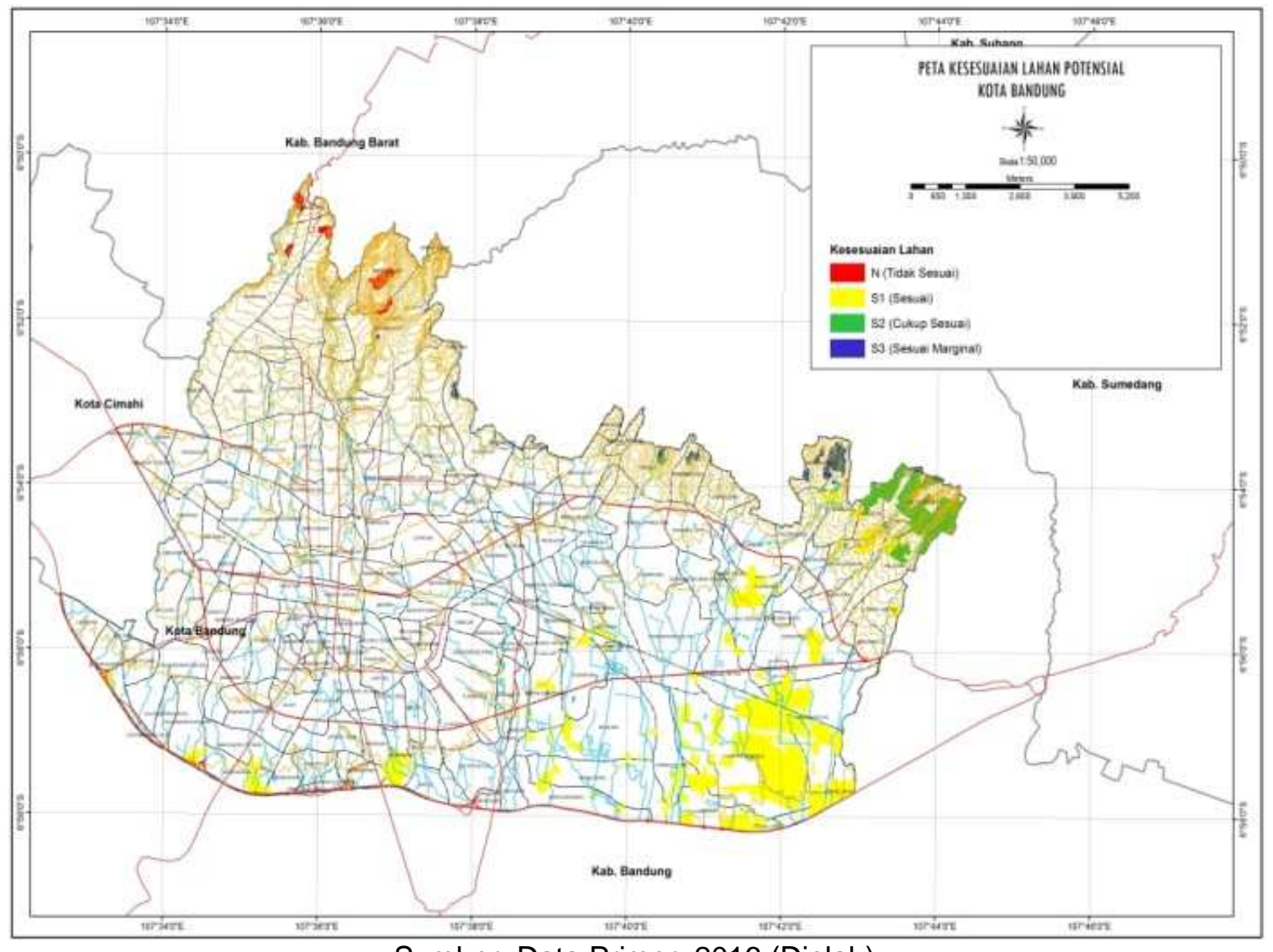

Sumber: Data Primer, 2016 (Diolah)

Gambar 3. Peta Lahan Pertanian Pangan Potensial Kota Bandung

Arahan komoditas pertanian berdasarkan analisis potensi lahan pertanian di Kota Bandung menunjukkan bahwa pada tingkat kesesuaian lahan S1 sampai S3 dapat ditanami oleh tanaman pangan, namun pada tingkat kesesuaian lahan S2 dan S3 perlu adanya usaha perbaikan untuk meningkatkan produktivitasnya. Pada kelas kesesuaian $\mathrm{N}$ dapat ditanami oleh tanaman tahunan, buahbuahan dan tanaman konservasi, karena pada lahan ini faktor kemiringan lereng yang menjadi faktor pembatas, apabila dijadikan lahan pertanian tanaman pangan maka akan berpengaruh pada kondisi tanah menjadi kurang subur, terjadinya erosi maupun terjadi banjir.
Tabel 5. Arahan Lahan Pertanian Pangan Berkelanjutan di Kota Bandung

\begin{tabular}{|c|c|c|c|}
\hline SPL & $\begin{array}{c}\text { Kesesu } \\
\text { aian } \\
\text { Lahan } \\
\text { Aktual }\end{array}$ & Faktor Pembatas & $\begin{array}{c}\text { Rekomendasi } \\
\text { Jenis Komoditas }\end{array}$ \\
\hline 1 & S1 & - & $\begin{array}{l}\text { Semua tanaman } \\
\text { pangan }\end{array}$ \\
\hline 2 & S2 & kemiringan lereng & sawah, jagung \\
\hline 3 & S3 & kemiringan lereng & $\begin{array}{l}\text { jagung, kedelai, } \\
\text { kacang tanah }\end{array}$ \\
\hline 4 & $\mathrm{~N}$ & kemiringan lereng & $\begin{array}{l}\text { Tanaman Tahunan, } \\
\text { buah-buahan }\end{array}$ \\
\hline 5 & $\mathrm{~N}$ & kemiringan lereng & $\begin{array}{l}\text { Tanaman Tahunan, } \\
\text { buah-buahan }\end{array}$ \\
\hline 6 & $\mathrm{~N}$ & kemiringan lereng & $\begin{array}{l}\text { Tanaman Tahunan, } \\
\text { konservasi }\end{array}$ \\
\hline 7 & $\mathrm{~N}$ & kemiringan lereng & $\begin{array}{l}\text { Tanaman Tahunan, } \\
\text { konservasi }\end{array}$ \\
\hline
\end{tabular}

66 Analisis Potensi Lahan Pertanian Pangan untuk Mendukung Ketahanan Pangan Kota Bandung 


\section{KESIMPULAN DAN SARAN}

\section{Kesimpulan}

Potensi luas lahan pertanian pangan di Kota Bandung yaitu dengan kelas kesesuaian lahan S1, S2 dan S3 mencapai $847,66 \mathrm{Ha}$. Dibandingkan dengan beberapa kota yang ada di Jawa Barat (rata-rata dibawah $500 \mathrm{Ha}$ ) ketersediaan lahan pertanian Kota Bandung lebih luas.

\section{Saran}

Beberapa saran yang direkomendasikan dalam kajian pemetaan lahan berkelanjutan Kota Bandung diantaranya:

1. Mempertimbangkan aspek sumberdaya, tidak semua parameter faktor pembatas lahan digunakan dalam kajian ini. Oleh karena itu, kedepan perlu melengkapi dengan parameter faktor pembatas lain seperti karakteristik mineral liat dan kimia tanah

2. Pemerintah Kota Bandung perlu mengeluarkan kebijakan untuk melindungi lahan pertanian pangan berkelanjutan yang sudah dihasilkan dari kajian inin seluas $841 \mathrm{Ha}$. Ini penting mengingat laju konversi lahan Kota Bandung cukup tinggi mengingat tipologinya sebagai wilayah urban. Salah satu kebijakan yang perlu dilakukan dengan cara pembelian lahan pertanian dari masyarakat oleh Pemkot Bandung. Strategi ini dipilih mengingat lahan pertanian yang ada bukan common resources tapi mayoritas ada pada ranah private goods

\section{UCAPAN TERIMA KASIH}

Penulis mengucapkan terima kasih kepada Kepala Pusat Studi Teknologi Tepat Guna Direktorat Riset dan Pengabdian Kepada Masyarakat Universitas Padjadjaran Bapak Prof. Dr. Roni Kastaman atas fasilitasi pembiayaan penelitian. Begitujuga kepada Ibu Kepala Dinas Pertanian dan Ketahanan Pangan Kota Bandung, atas masukan dan perbaikan hasil kajian.

\section{DAFTAR PUSTAKA}

FAO. 1976. A Framework for Land Evaluation. Soil Resources Managementand Conservation Service Land and Water Development Division. FAOSoil Bulletin No. 32. FAO-UNO, Rome

Hardjowigeno, S., N. Suharta, H. Subagyo, D. Djaenudin, dan Marsoedi Ds.1994. Evaluasi lahan untuk Irigasi. Lap.Tek.No. 8 Ver. 1.Proy. LREPPuslittanak, Bogor.

Hendrickson, M dan Porth, M. 2012. Urban Agriculture - Best Practices and Possibilities. University of Missouri

Peraturan Daerah Kota Bandung No. 3 Tahun 2014 Tentang Rencana Pembangunan Jangka Menengah Daerah (RPJMD) Kota Bandung Tahun 2013-2018

Pusat Data dan Informasi Kementerian Pertanian. 2015. Statistika Lahan PertanianTahun 2010-2014. Sekretariat Jenderal Kementerian Pertanian. Jakarta

Pusat Penelitian Tanah dan Agroklimat. 1993. Petunjuk Teknis EvaluasiLahan. Pusat Penelitian Tanah dan Agroklimat

UNDP (United Nations Development Programme). 2004. Urban AgricultureFood, Jobs and Sustainable Cities. New York, USA.

Sys, C. 1985. Land Evaluation. State University of Ghent.

Sys, C., E. Van Ranst, J. Debaveye, and F. Beernaert. 1993. Land Evaluation.Crop Requirements Part III. Agricultural Publication No. 7. GeneralAdministration for Development Corp. 1050 BrusselsBelgium

UU No. 7 tahun 1996 tentang Pangan

UU No. 41 Tahun 2009tentang Perlindungan Lahan Pertanian Pangan Berkelanjutan 